\title{
Characteristics of the Bohai Sea oil spill and its impact on the Bohai Sea ecosystem
}

\author{
GUO Jie ${ }^{1,2,3^{*}}$, LIU Xin ${ }^{1,2,3} \&$ XIE Qiang ${ }^{4,5}$ \\ ${ }^{1}$ Key Laboratory of Coastal Zone Environmental Processes, Chinese Academy of Sciences, Yantai 264003, China; \\ ${ }^{2}$ Shandong Provincial Key Laboratory of Coastal Zone Environmental Processes, Yantai 264003, China; \\ ${ }^{3}$ Yantai Institute of Coastal Zone Research, Chinese Academy of Sciences, Yantai 264003, China; \\ ${ }^{4}$ State Key Laboratory of Tropical Oceanography, South China Sea Institute of Oceanology, Chinese Academy of Sciences, Guangzhou 510301, \\ China; \\ ${ }^{5}$ Sanya Institute of Deep-sea Science and Engineering, Chinese Academy of Sciences, Sanya 572000, China
}

Received April 26, 2012; accepted June 11, 2012; published online July 16, 2012

\begin{abstract}
In this paper, ENVISAT ASAR data and the Estuary, Coastal and Ocean Model was used to analyze and compare characteristics of the Bohai Sea oil spill. The oil slicks have spread from the point of the oil spill to the east and north-western Bohai Sea. We make a comparison between the changes caused by the oil spill on the chlorophyll concentration and the sea surface temperature using MODIS data, which can be used to analyze the effect of the oil spill on the Bohai Sea ecosystem. We found that the Bohai Sea oil spill caused abnormal chlorophyll concentration distributions and red tide nearby area of oil spill.
\end{abstract}

ENVISAT ASAR, MODIS, oil spill, chlorophyll, sea surface temperature

Citation: Guo J, Liu X, Xie Q. Characteristics of the Bohai Sea oil spill and its impact on the Bohai Sea ecosystem. Chin Sci Bull, 2013, 58: 2276-2281, doi: $10.1007 / \mathrm{s} 11434-012-5355-0$

Conservation of the marine environment is of public concern. Oil spills cause serious damage to the marine environment [1], especially in coastal waters. China's Bohai Sea is an inland sea surrounded by the Liaodong and Shandong peninsulas. It connects to the Yellow Sea and covers 77000 $\mathrm{km}^{2}$. The average depth of the Bohai Sea is $18 \mathrm{~m}$ and is dominated by mud and silt-mud sediments. The Bohai Sea consists of Laizhou Bay, Bohai Bay, Liaodong Bay, and the central basin. The sea is nearly enclosed by shallow waters and has a high, rich-quality fishery, a harbor, petroleum, sea salt resources and landscapes. However, its own water exchange is abnormally slow. According to expert estimates, the entire cycle takes about 30 years, and its environmental self-purification capacity is very limited (http: //news.ycwb. com/2011-07/07/content_3483069.htm).

There are about 100 ports along the Bohai Sea coast. The Bohai Sea is very rich in oil and gas resources, some

*Corresponding author (email: jguo@yic.ac.cn) sources of which are the Victory, Dagang, and Liaohe oil fields. The offshore oil fields have been integrated into one, becoming China's second largest oil field. Oil spill pollution is a serious threat to the Bohai Sea, and its ecology has become a focus of attention. Synthetic aperture radar (SAR) is an effective microwave sensor to detect oil spills, which can image ocean surfaces during the day and night with high resolution and large coverage, independent of cloud cover [2]. Oil spill detection using SAR images relies on the oil slick to decrease the sea surface backscatters which results in a dark formation that contrasts with the brightness of the surrounding spill-free sea. The oil spill appears as dark areas in SAR images, and these areas are usually referred to as look-alikes, whose presence makes detection a challenging task. This phenomenon gives rise to look-alikes which may include biogenic films, areas of low wind $(<3 \mathrm{~m} / \mathrm{s})$, windshadow near the coastal regions, rain cells, upwelling, internal waves, and oceanic or atmospheric fronts. The semiautomatic and automatic detection algorithms based on 
neural networks, multi-scale image segmentation and fuzzy logic have been developed to detect oil slicks with SAR data [3-7]. In this paper, we detected an oil slick in the Bohai Sea using ENVI and Nest4A software. We used ocean dynamic models, ASAR data and MODIS data to analyze the characteristics of the oil spill and the potential impacts of the oil spill event on Bohai Sea ecological environment.

\section{Data and methods}

\subsection{Study area and data}

In the second half of 2011, an oil spill took place in the Bohai Sea near $38^{\circ} \mathrm{N}, 120.0^{\circ} \mathrm{E}$. The spill lasted for some months and caused a great deal of concern because it occurred very close to shore. The region under investigation is located between $117^{\circ} \mathrm{E}$ and $122^{\circ} \mathrm{E}$, and $37^{\circ} \mathrm{N}$ and $40^{\circ} \mathrm{N}$. ENVISAT ASAR images data are used to detect this oil spill in this study (Table 1).

\subsection{Methods}

In this paper, we used ENVISAT ASAR data and the Nest4A image processing system to detect the oil spill. The film could be reduced to the normalized radar cross sections (NRCS) of sea surface that were dark on the SAR image formation, contrasting with the brightness of the surrounding spill-free sea. Therefore, we attributed the dark patches on SAR images to the oil spill based on the patches' occurrence, sizes and shape. The texture information (shape, length, area, perimeter, edge gradient, contrast and complexity) and contextual information (location and distance to both the coastline and the bright point associated with ship with a certain probability, the sea surface wind and the current) were used to distinguish oil spill to look-alikes [1].

Several image-processing techniques were used, including re-projection, a refined Lee Filter (Window $3 \times 3$ ), and mask area computation (Figure 1). We had 6 ENVISAT ASAR images of the oil spill in Bohai Sea (Table 1). Figure 2 shows the positions and oil slick areas of 6 ENVISAT ASAR images. Using ASAR Image observations on June 11 (Figures 1 and 2), we found that the oil slicks spread from the point of the oil spill to the north then to the east or west Bohai Sea. The oil slick drifted from east to west in the

Table 1 Remote sensing image data used to detect the oil spill in the Bohai Sea

\begin{tabular}{cccc}
\hline Name & Date & Type of polarization & Spatial resolution \\
\hline ASA_WSM & 11 June, 2011 & vertical polarization & $150 \mathrm{~m} \times 150 \mathrm{~m}$ \\
ASA_WSM & 19 June, 2011 & vertical polarization & $150 \mathrm{~m} \times 150 \mathrm{~m}$ \\
ASA_IMM & 8 July, 2011 & vertical polarization & $30 \mathrm{~m} \times 30 \mathrm{~m}$ \\
ASA_IMM & 18 August, 2011 & vertical polarization & $30 \mathrm{~m} \times 30 \mathrm{~m}$ \\
ASA_WSM & 21 August, 2011 & vertical polarization & $150 \mathrm{~m} \times 150 \mathrm{~m}$ \\
ASA_IMM & 3 September, 2011 & vertical polarization & $30 \mathrm{~m} \times 30 \mathrm{~m}$ \\
\hline
\end{tabular}

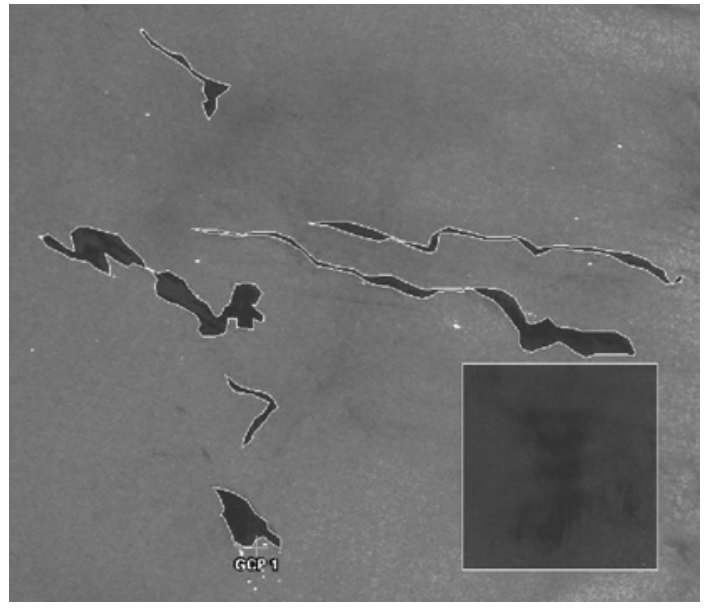

Figure 1 The irregular curve surrounding the area is the oil slick. The GCP1-oil spill is located at the point of the spill, and the rectangle shows the look-alike areas (observed on 11 June 2011).

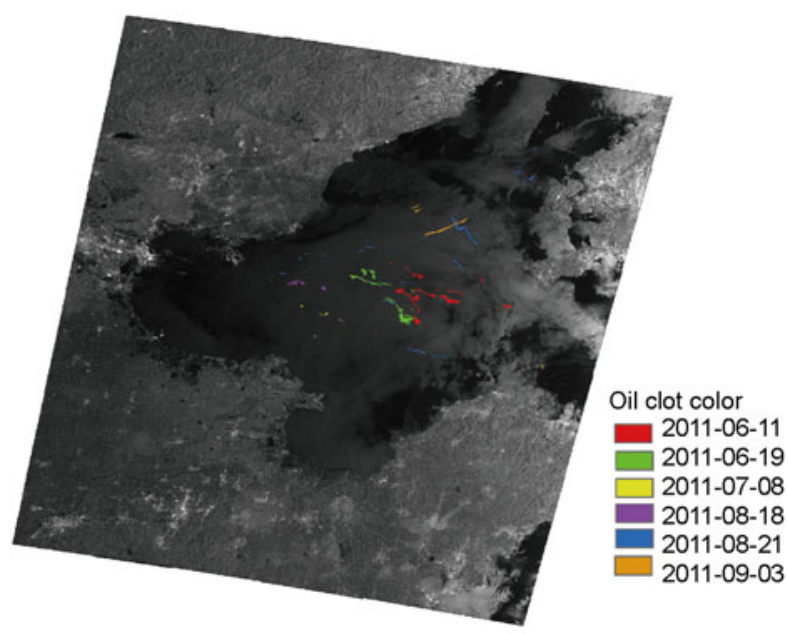

Figure 2 Oil slick distribution from six ENVISAT-ASAR images.

Bohai Sea, according to ASAR image observations on 11 June, 19 June, and 8 July 2011. Moreover, the oil slicks drifted from the west to northwest Bohai Sea as measured on 18 August, 21 August (wind speed $>8 \mathrm{~m} / \mathrm{s}$ ), and 3 September, 2011. Some oil slicks drifted to the Bohai Strait. We found that only an area of $477.4 \mathrm{~km}^{2}$ was polluted in the Bohai Sea, based on observations from 6 discontinuities ENVISAT ASAR images (Table 2 shows the oil spill areas derived from 6 ENVISAT ASAR images).

Table 2 Oil spill area distributions over 6 days in the Bohai Sea

\begin{tabular}{lc}
\hline \multicolumn{1}{c}{ Date } & Oil spill area $\left(\mathrm{km}^{2}\right)$ \\
\hline 11 June, 2011 & 164.0 \\
19 June, 2011 & 141.2 \\
8 July, 2011 & 13.3 \\
18 August, 2011 & 29.2 \\
21 August, 2011 & 93.4 \\
3 September, 2011 & 36.3 \\
\hline
\end{tabular}




\section{Characteristics of the oil spill and of the simulation}

This oil spill was located in the central South Bohai Sea. The crude oil of Bohai Sea has "three high and four low" characteristics. These characteristics refer to high-density, high viscosity, high colloid content, low freezing point, low wax content, and low bitumen content.

Most of the wind speeds in oil spill areas during 4 June 2011-5 July 2011 were less than $8 \mathrm{~m} / \mathrm{s}$ (Figure 3, which defines the due north direction as positive). In general, wind speeds smaller than $3 \mathrm{~m} / \mathrm{s}$ also induce dark areas in the SAR images (when the wind speeds are more than $8 \mathrm{~m} / \mathrm{s}$, they induce dark areas and the SAR images break up), which can affect the oil spill detection.

To simulate the drift of oil spilled from the seabed close to the points of Bohai Sea, a three-dimensional oil transport model including a variety of processes such as spreading, stranding, evaporation and emulsion was developed based on ECOM (Estuary, Coastal and Ocean Model). For a three dimensional model, rectilinear grids were generated horizontally to cover the whole domain ranging from $117.5^{\circ} \mathrm{E}$ to $122.5^{\circ} \mathrm{E}$ and from $37^{\circ} \mathrm{N}$ to $41^{\circ} \mathrm{N}$ in the local coordinate system. The grid cell was $1.67^{\prime}$ longitude by $1.67^{\prime}$ latitude. The mesh comprised 180 cells ( $x$ direction) and 144 cells ( $y$ direction). Ten layers were designated vertically. Bathymetry data were downloaded from ETOPO1 Global Topography (NOAA). Coastal line data were extracted from the National Geographical Data Center (NGDC). We set up two different simulations according to wind conditions. All simulations started on 4 June at 20:00 and ended on 21 July at 20:00. All simulations lasted $47 \mathrm{~d}$. In the first simulation, wind field data came from the Penglai Meteorological station (Figure 3). It is hour-varied mode. The wind data for the second simulation were assumed to be averaged monthly while considering the strong typhoon occurring in the specific time period in this area. For simulations, amplitudes and phases for 4 major harmonic constants (M2, S2, K1 and

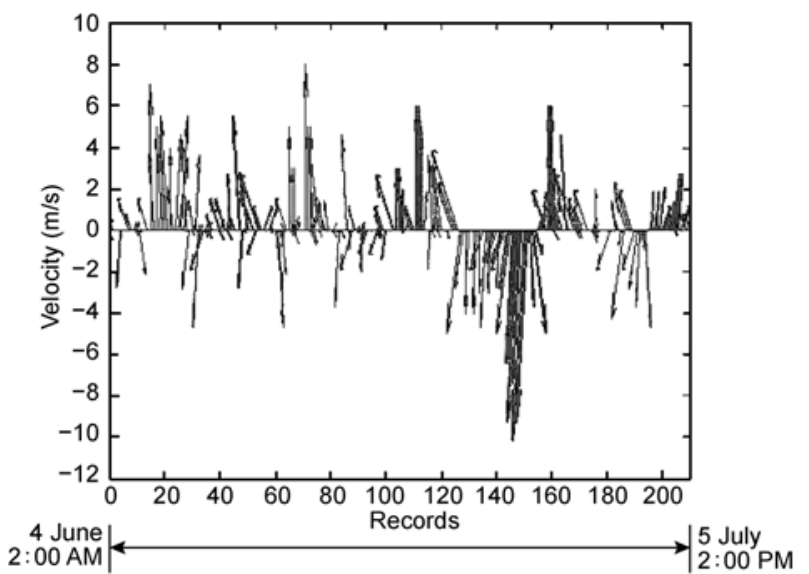

Figure 3 Wind field of Bohai Sea (actual measurement) from 4 June to 5 July, 2011.
O1) were interpolated along the open boundary to generate initial conditions driving the tide. The spill was assumed to be continuous in the specific time duration. The spill rate was simulated to be 100 particles every $180 \mathrm{~s}$. In total, there were 10000 particles representing 1500 barrels of heavy oil released during $5 \mathrm{~h}$. Using the Lagrangian algorithm, surface oil particles drifted by both wind and tidal currents $[8,9]$. Three-dimensional simulations plus time as results are shown in Figure 4. For the simulations, we assumed that
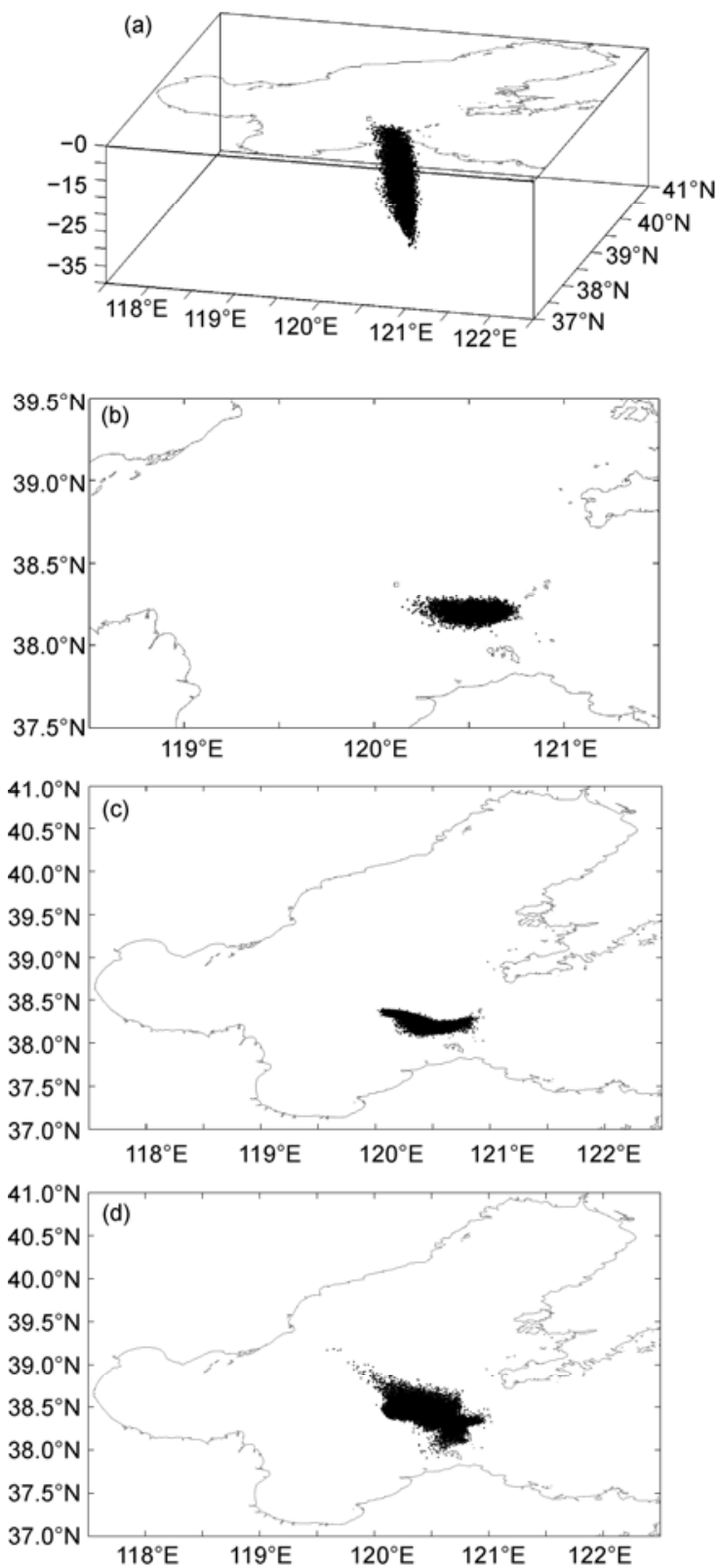

Figure 4 Results of the simulations. (a) Three-dimensional view of the oil trajectory on 16 July, 2011 with a vertical distribution of oil in water column; (b) horizontal distribution of oil on 16 July, 2011 in a zoomed map with a tendency to flow east; (c) horizontal distribution of oil on 21 July, 2011 with a tendency to flow east and southeast; and (d) horizontal distribution of oil on 21 July, 2011 driven by a monthly-averaged mode of wind. Oil mostly flowed southeast with only few areas scattered towards the northwest. 
there was no combat against oil spill in waters. Given the wind data (hour varied mode), Figure 4(a)-(c) predicted that the oil mostly flowed east and southeast, which threatened particular islands including Tuoji Island off the Yantai coastal zones. In contrast, Figure 4(d) predicted that most of the oil had a southeastern trajectory and only tended west or northwest under a monthly-averaged mode of wind.

\section{Results and discussion}

We found that the area of the oil spill was located in the central Bohai Sea (Figures 1 and 2). Vessels in this area easy brought the oil slicks to other regions, which expanded the scope of pollution and in doing so, the range vessels traveled. We only observed pollution on the sea surface, so we were unable to observe how many small oil droplets became suspended in the water and to what degree the dissolved petroleum hydrocarbons were absorbed in the solid particle sink in seawater. We know that plankton, fish eggs, Parr and shellfish are vulnerable to pollution. On one hand, these species are particularly sensitive to toxic effects of oil; they also may be affected in even lower oil concentrations.
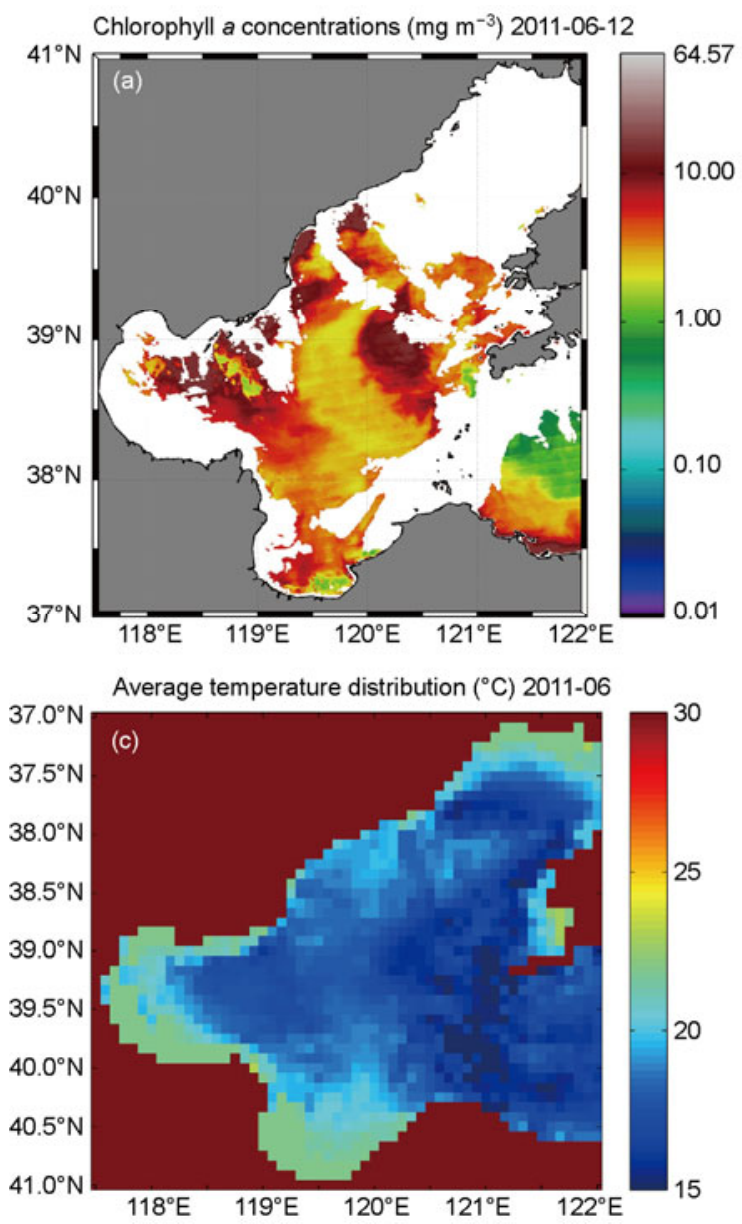

On the other hand, it is impossible for them to just avoid the contamination area like a marine animal (such as the seal, Chelonian and so on). In addition, the oil film on the sea surface affects phytoplankton photosynthesis by obscuring the sun, making it difficult for the plankton-eating marine life to survive (Figures 5(a), (b) and 6(a), (b)). Once the plankton is contaminated, other advanced species in the food web are threatened because of bioaccumulation of pollution. In this way, human health also would be directly affected by the "carcinogenic" threat.

Figure 5(a) and (b) shows a comparison between chlorophyll distributions on 12 June, 2009 and 12 June, 2011. Comparing Figure 5(a) and (b), we found that the chlorophyll concentrations in a nearby area of the oil spill in Figure 5(a) were significantly increased to $10 \mathrm{~cm}^{3} / \mathrm{mg}$ in comparison with Figure 5(b). Figure 5(c) and (d) shows a comparison between sea surface average temperature in June, 2011 and average temperature from June, 2000 to June, 2010 (except 2003). We found that the temperature of the Bohai Sea was higher (except middle of Bohai Sea) in June 2011 (Figure $5(c))$ compared with that of the same period (Figure 5(d)). From Figure 6, we found that the abnormal chlorophyll concentration areas on 24 June 2011 in Figure 6(a) was

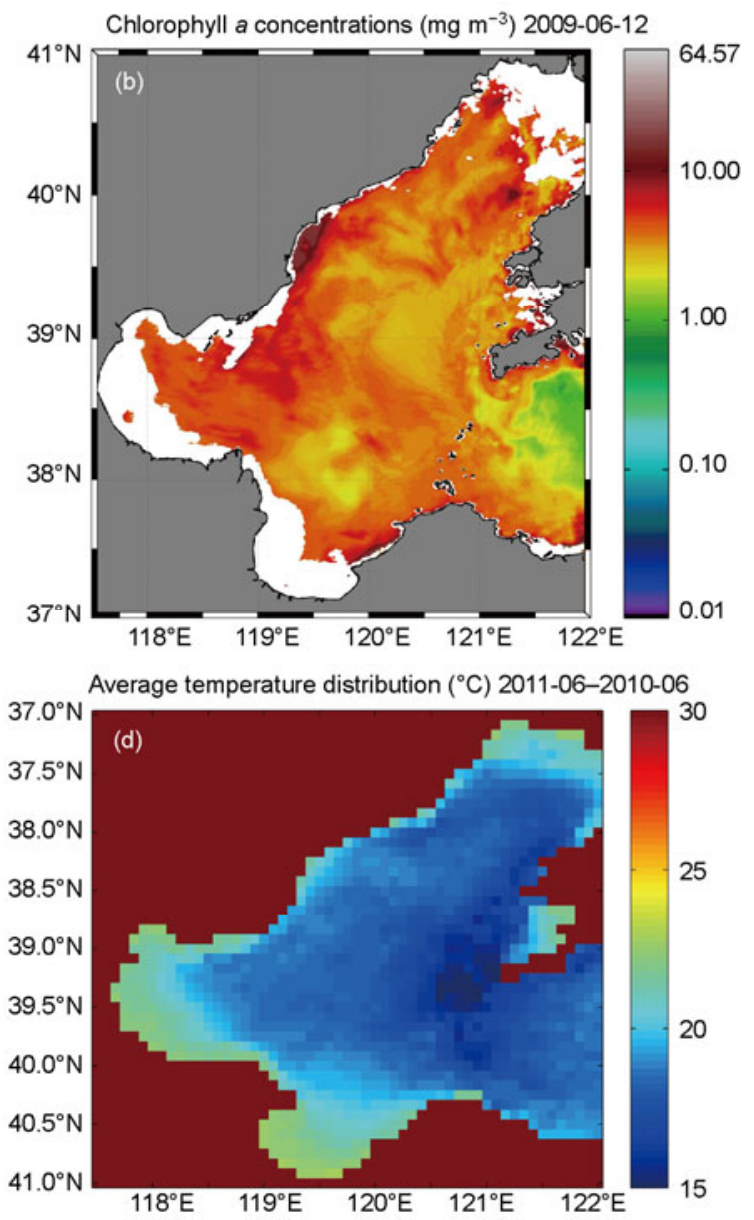

Figure 5 Chlorophyll and sea surface temperature of Bohai Sea distributions for chlorophyll on 12 June 2011 (a), chlorophyll on 12 June 2009 (b), average temperature in June 2011 (c), and average temperature from June 2000 to June 2010 (except 2003) (d). 

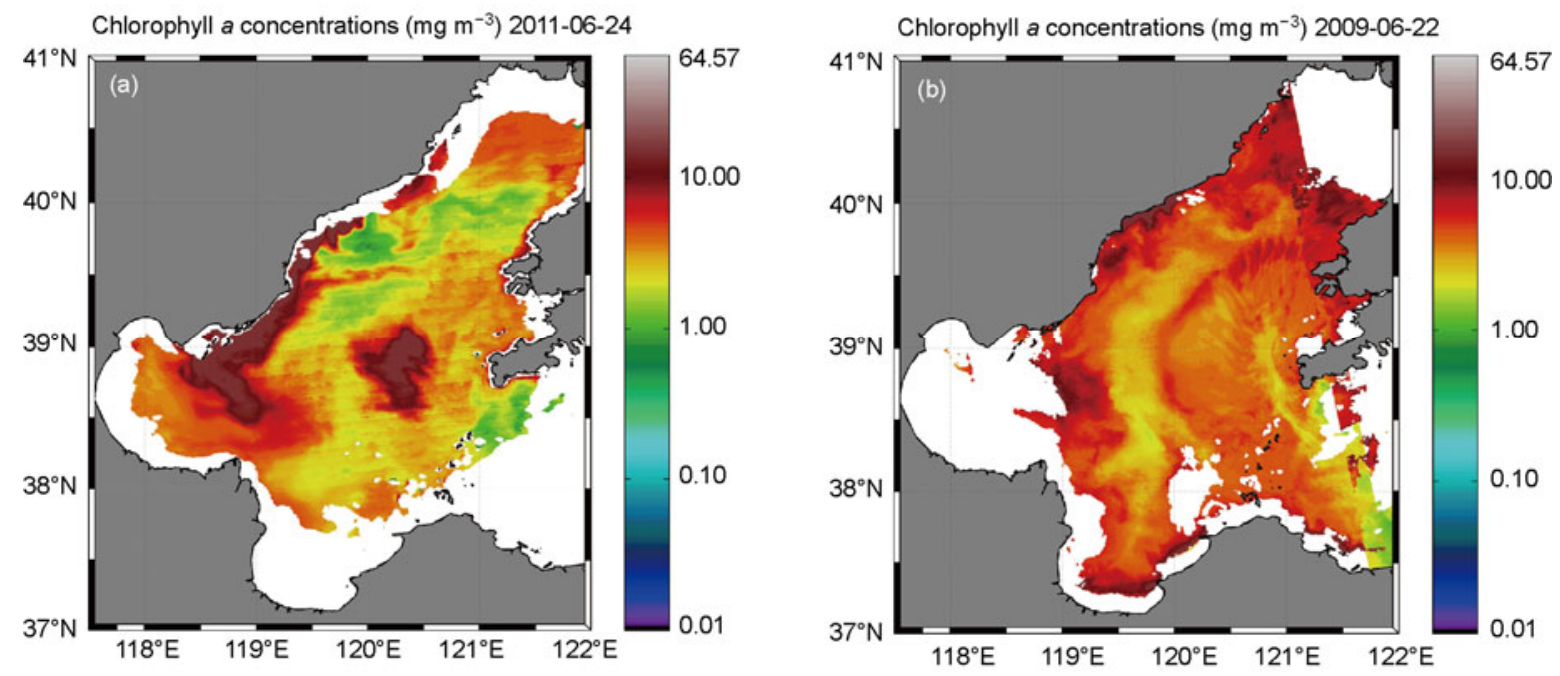

Figure 6 Bohai Sea Chlorophyll distributions for chlorophyll on 24 June 2011 (a), and chlorophyll on 22 June 2009 (b).

generally higher than other regions in the same period in Figure 6 (b) in 2009. The event made this region's chlorophyll concentration abnormal and induced a red tide (Central Bohai Sea see Figure 7 and Temple Island Islands nearby see Figure 8).

From observation of ENVISAT ASAR images and the ECOM simulation, we found that some oil slicks drifted from the point of the oil spill to the northwest Bohai Sea. Some slicks drifted to the east marine outfall of Bohai Sea, but most slicks remained near the point of the oil spill in the Bohai Sea as the flow field speeds are small (Table 3, data from National Marine Environmental Forecasting Center).

The oil spill radiated to the ecologically sensitive area of the Bohai Sea. There are more than 30 islands of varying size in the Bohai Strait, called the Miaodao Islands. Because they are located at the intersection of water masses in the Bohai Sea and Yellow Sea, they have unique biodiversity and distributions of Chang Island birds, and seals of

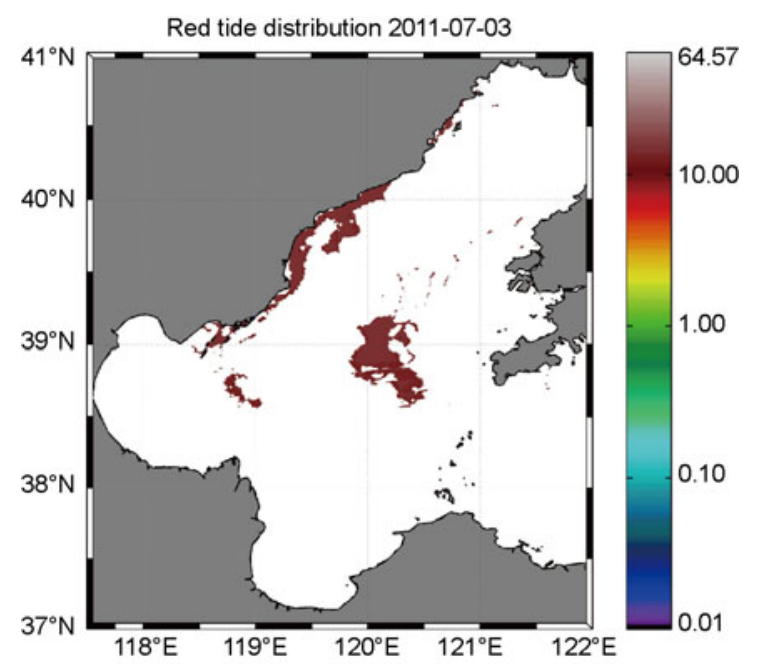

Figure 7 Extent of the red tide in the Bohai Sea on 3 July 2011.

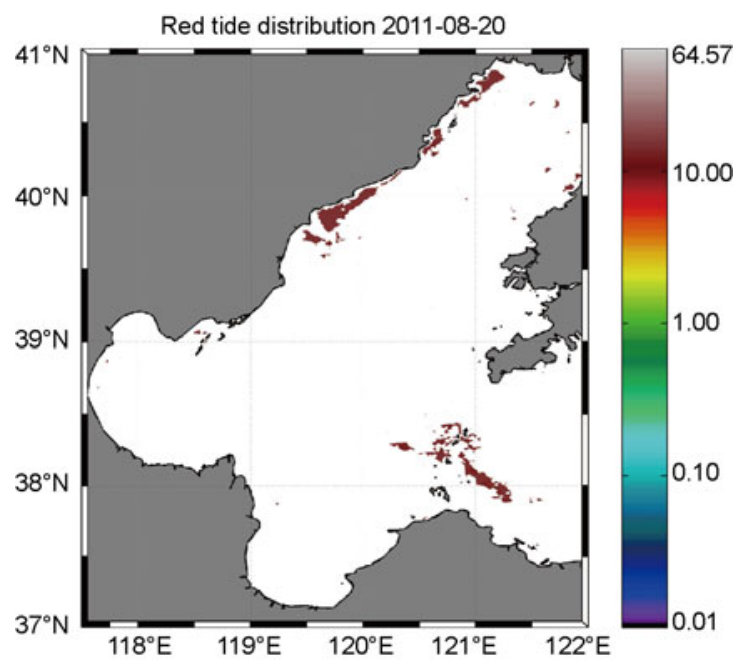

Figure 8 Extent of the red tide in Bohai Sea on 20 August 2011.

Table 3 Oil spill area current velocity distributions over 6 days in the Bohai Sea

\begin{tabular}{lc}
\hline \multicolumn{1}{c}{ Date } & Current field speed $(\mathrm{m} / \mathrm{s})$ \\
\hline 11 June, 2011 & $1.0-1.2$ \\
19 June, 2011 & $0.2-0.6$ \\
8 July, 2011 & $0.2-0.4$ \\
18 August, 2011 & $0.4-0.8$ \\
21 August, 2011 & $0.4-0.6$ \\
3 September, 2011 & $0.2-0.4$ \\
\hline
\end{tabular}

Miaodao Islands belonging to state and provincial nature reserves. Because the Bohai Sea connects with the Yellow Sea only through the Bohai Strait, and water exchanges with other water bodies slowly, this accident has a persistent influence on the ecology of the Bohai Sea. Because the Bohai Sea is a major nesting site, the results of contamination are that the supply of young fish will decrease. Because of the 
winter low water temperatures in the Bohai Sea, fish migrate to the Yellow Sea from the Bohai Sea, so the Yellow Sea may be affected by the oil spill for a long period. The Bohai Sea ecosystem is already fragile [10], and the oil spill occurrence makes this undoubtedly worse.

The work was supported by the State Key Laboratory of Tropical Oceanography, South China Sea Institute of Oceanology, Chinese Academy of Sciences, the CAS/SAFEA International Partnership Program for Creative Research Teams-Typical Environmental Processes and Resources Effects of Coastal Zone, Key Laboratory of Ocean Circulation and Waves, Institute of Oceanology, Chinese Academy of Sciences, the Natural Science Fund of Shandong Province (2009ZRA06046), and the National Natural Science Foundation of China (41176160). ASAR data were provided by the European Space Agency. MODIS data were provided by NASA MODIS website.

1 Fan K, Zhang Y, Lin H. Satellite SAR analysis and interpretation of oil spill in the offshore water of Hong Kong. Ann GIS, 2010, 16: 269-275

2 Brekke C, Solberg A H S. Oil spill detection by satellite remote sensing. Remote Sens Environ, 2005, 95: 1-13

3 Zhang B, Perrie W, Li X F, et al. Mapping sea surface oil slicks using
RADARSAT-2 quad-polarization SAR image. Geophys Res Lett, 2011, 38: L10602

4 Frate F D, Petrocchi A, Lichtenegger J, et al. Neural networks for oil spill detection using ERS-SAR data. IEEE Trans Geosci Remote Sens, 2000, 38: 2282-2287

5 Solberg A H S, Brekke C, Husoy P O. Oil spill detection in Radarsat and Envisat SAR images. IEEE Trans Geosci Remote Sens, 2007, 45: 746-755

6 Garcia-Pineda O, Zimmer B, Howard M, et al. MacDonald. Using SAR images to delineate ocean oil slicks with a texture-classifying neural network algorithm (TCNNA). Can J Remote Sens, 2009, 35: 411-421

7 Liu P, Zhao C, Li X, et al. Identification of ocean oil spills in SAR imagery based on fuzzy logic algorithm. Int J Remote Sens, 2010, 31: 4819-4833

8 Wei H, Hainbucher D, Pohlmann T, et al. Tidal-induced Lagrangian and Eulerian mean circulation in the Bohai Sea. J Mar Syst, 2004, (44): 141-151

9 He Y, Lu X, Qiu Z, et al. Shallow water tidal constituents in the Bohai Sea and the Yellow Sea from a numerical adjoint model with TOPEX/POSEIDON altimeter data. Cont Shelf Res, 2004, (24): $1521-1529$

10 Guo J, Xie Q, Chen Z B. Remote sensing information extraction of Laizhou Bay environment pollution (in Chinese). Mar Sci, 2012, 36: $119-128$

Open Access This article is distributed under the terms of the Creative Commons Attribution License which permits any use, distribution, and reproduction in any medium, provided the original author(s) and source are credited. 